\author{
우리나라 다랑어연승어업에 의한 \\ 인도양해역 눈다랑어(Thunnus obesus) 및 \\ 황다랑어( Thunnus albacares) 의 CPUE 표준화 \\ 권유정 - 안두해' - 이재봉 ${ }^{2 *}$ - 장창익 · 문대연' \\ 부경대학교 대학원 수산물리학과 \\ ${ }^{1}$ 국립수산과학원 해외자원과, ${ }^{2}$ 국립수산과학원 자원연구과
}

\title{
Standardization of CPUE for bigeye(Thunnus obesus) and yellowfin(Thunnus albacares) tunas by the Korean longline fishery in the Indian Ocean
}

\section{Youjung Kwon, Doo Hae AN¹, Jae Bong LeE ${ }^{2 *}$, Chang Ik Zhang and Dae Yeon Moon}

Department of Fisheries Physics, Graduate School, Pukyong National University, Busan, 608-737, Korea

${ }^{1}$ Distant Water Fisheries Resources Division, National Fisheries Research and

Development Institute, Busan, 619-902, Korea

${ }^{2}$ Fisheries Resources Research Division, National Fisheries Research and Development Institute,

$$
\text { Busan, 619-902, Korea }
$$

This study standardized catch per unit effort(CPUE) of the Korean longline fishery, which has been used to assess the status of stock as an index of abundance, for bigeye and yellowfin tunas in the Indian Ocean. The Generalized Linear Model(GLM) was used to analyze the fishery data, which were catch in number and effort data collected each month from 1971 to 2007 by $5 \times 5$ degree of latitude and longitude. Explanatory variables for the GLM analysis were year, month, fishing area, number of hooks between floats(HBF), and environment factors. The HBF was divided into three classes while the area was divided into eight subareas. Although sea surface temperature(SST) and southern oscillation index(SOI) were considered as environmental factors, only SST was used to build a model based on statistical significance. Standardized CPUE for yellowfin tuna showed a declining trend, while nominal CPUE for the species showed an increasing trend.

\footnotetext{
*Corresponding author: leejb@nfrdi.re.kr, Tel: 82-51-720-2296, Fax: 82-51-720-2277
} 
Key words : Bigeye tuna Thunnus obesus, Yellowfin tuna Thunnus albacares, Standardized CPUE, Generalized Linear Model, Indian Ocean

\section{서 론}

다랑어 류는 경 골어 강(Class Osteichthyes) 농어 목(Order Perciformes) 고 등어 과(Family Scombridae)에 속하는 어류로, 눈다랑어, 황다랑어, 닐 개다랑어, 가다랑어 및 참다랑어 등이 있다. 이들 은 모두 고도회유성 어종으로 외양성이며, 각 대 양별로 하나 혹은 두개의 계통군으로 구성되어 있다(FAO, 1997). 특히, 눈다랑어(T. obesus) 는 전 대양의 온대 및 열대해역에 광범위하게 분포하 고, 대양의 표층 근처 또는 중층 수역(수심 $0-$ $250 \mathrm{~m})$ 에서 생 활한다(FAO, 2003). $10^{\circ} \mathrm{N}-10^{\circ} \mathrm{S}$ 사이 동부태평양에서는 연 중 산란을 하나 북반 구에서 는 4-9월, 남반구에서 는 $1-3$ 월이 주 산 란기이다. 황다랑어(T. albacares)는 전 대양의 열대 및 아열대 해역에 걸쳐 광범위하게 분포하 며, 주로 표층에서부터 수온약층을 경 계로 그 주 위에서 서식한다(FAO, 2003). 눈다랑어와 황다 랑어는 전 대양에 분 포하기 때 문에 각 서식해역 에 따라 관리하는 위 원회 가각각 다르며, 인도양 에서는 인 도양다랑어위 원회(Indian Ocean Tuna Commission, IOTC) 에서 관리하고 있다.

인 도양해역 에서 눈 다랑어와 황다랑어는 1950 년대 초부터 어획되기 시작하였으며 최근에는 전 세 계 38 개국이 어 획하여 50 만톤의 어획량 수 준을 보이고 있는데(FAO, 2007), 이중 우리나라 를 비롯한 6 개 국이 총어획 량의 $52 \%$ 를 차지하고 있다. Fig. 1(a)는 인도양 해역에서 의 눈다랑어 및 황다랑어 어획량 상위 6 개국에 대한 어획량 변 동을 보여주고 있다. 1980 년대 초반까지는 10 만톤 이하의 어획량 수준을 보이고 있다. 어업 초반부터 1960 녁대 중반까지는 대부분 일본이 어획하였으며, 점차 우리나라, 대 만, 인 도네시아 등의 국가에서도 어획에 참여하였다. 1980 년 중
반부터 인 도네시아, 프랑슥 스페인 의 어획 참여 로 인도양해역에서 눈 다랑어와 황다랑어의 어 획 량이 증가하여 최근에 는 30 만톤 정 도가 어획 되고 있다.

인 도양해역 에서 의 우리나라 다랑어 연승어업 은 1960년대 중반부터 시작되어 1970년대 중반 부터 1980 년 대 초반까지는 총어획 량의 절반 이 상을 우리나라가 차지하였다. 우리나라 다랑어 연 승어업의 어획량은 조업시작 이후 꾸준히 증 가하다가, 1977 년 6 만 5 천 톤을 기 점으로 감소하 여 1998년 이후부터는 1 만톤 내외의 낮은 어획 량을 나타내고 있다. Fig. 1(b)와 같이 우리나라 다랑어 연승어업 에 의 한 주어획 대상종은 눈 다랑 어 와 황다랑어이며, 이외에 도 날개다랑어, 남방 참다랑어, 가다랑어 등이 부수적으로 어획되고 있다.

국제수산기구에서 다랑어 자원을 대상으로

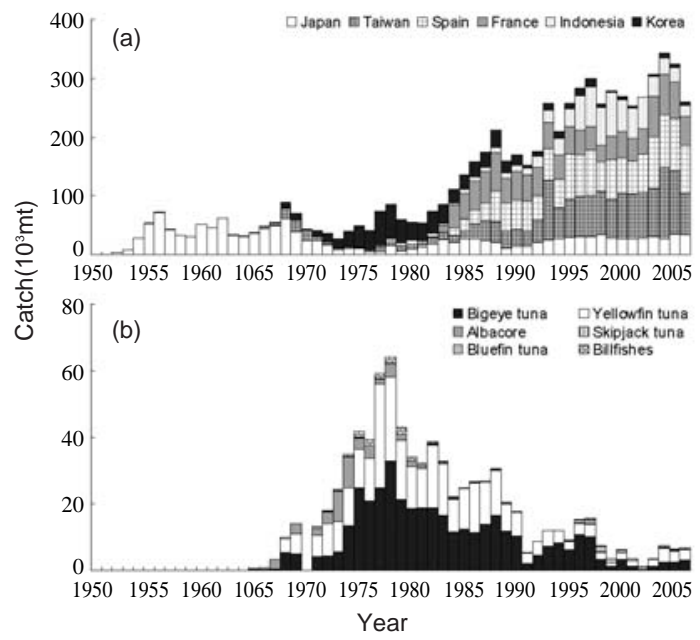

Fig. 1. Annual catches of bigeye and yellowfin tunas by country (a) and of Korean longline fishery by species (b) in the Indian Ocean(FAO, 2007). 
수행되는 자원평가의 대 부분은 풍도지수를 사 용한 개체군역학모델에 의해 자원상태가 평가 되고 있으며(Polacheck et al., 1993), 풍도지수로 는 단위노력 당어 획 량(catch per unit effort, CPUE)이 널리 사용되고 있다(Maunder, 2001). 하지만, $\mathrm{CPUE}$ 는 개체군의 풍도뿐만 아니라 외 부요소들(계절, 어장, 환경요소, 선박크기, 경제 적 요소 등)에 의해 변 동될 수 있기 때문에 수산 자원의 풍도를 진단할 때는 이러한 외부요소들 의 영향을 제 거하여 표준화된 어획노력량을 이 용해야 한다(Hilborn and Walters, 1992; Maunder and Starr, 1995; Hinton and Nakano, 1996). 보다 정 확한 다랑어의 자원상태를 평 가하기 위해서 는 CPUE를 표준화하여 개체군역학모델 을 사용 하여야 한다(Hinton and Nakano, 1996).

지금까지 우리나라 다랑어 연 승어업에 의해 어획되는 인도양해역 눈다랑어와 황다랑어의 어획자료가 포함된 자원평 가는 지금까지 수행 된 바가 없으며, IOTC에서는 일본 및 대만의 어 획자로를 사용한 눈다랑어 및 황다랑어 자원평 가 결과를 채택해 오고 있다. 이에 1970년대 초 반부터 수집된 본 해역의 어장환경 및 우리나라 다랑어연승어업의 어획자료를 힐용하여 향후 수행될 다랑어 자원평가를 위한 기반연 구의 일 환으로 CPUE 의 표준화 연 구가 필요하다.

따라서, 본 연구에서는 인도양해역의 우리나 라 다랑어연승어업에서 어획되는 눈다랑어 및 황다랑어의 시공간적 변 동을 살펴보고, 계절성, 어장환경, 어구 등의 외부요소들이 미친 영향에 대하여 CPUE를 표준화하였다. 마지막으로 표 준화된 $\mathrm{CPUE}$ 를 통해 눈다랑어와 황다랑어간의 어획관련성을 비교하였다.

\section{자료 및 방법}

인 도양해역 에서 의 우리나라 다랑어 연승 어 획 자료는 국립수산과학원 에서 1971 - 2007년간 출 어선 선장들로부터 수집한 조업일지에 기재된 어획관련 자료를 위 - 경도별 $5^{\circ} \times 5^{\circ}$ 단위로 나
누어 정리하였다. 대 상해역은 인도양다랑어위 원 회(IOTC)의 관리해역인 51 번 과57 번 해구를 7 개의 소해역으로 나누 었던 Okamoto and Shono(2006)의 해구 구분을 근간으로 본 연구에 서는Fig. 2 와 같이 7 번 소해역을 추가하여 전체 8 개의 소해역으로 구분하였다. CPUE 표준화에 사용된 어획관련 자로는 눈다랑어 및 황다랑어 의 어획미수, 노력랑(낚시수), 뜸과 뜸간의 낚시 바늘수(number of hooks between floats, HBF) 및 환경인자들을 사용하였다. 여기서 $\mathrm{HBF}$ 는 낚시 바늘수에 따라 9 개 이하, 10 에서 15 개, 16 개 이 상으로 크게 3 개의 그룹으로 나누었으며, 환경 인자는 남방진동계수(southern oscillation index, $\mathrm{SOI})$ 와 어획시점의 표층수온 자료(SST)를 사용 했다.

눈다랑어와 황다랑어의 연 승어 업 CPUE에 영 향을 미치는 인자를 구명하기 위해 일 반선형모 델(Generalized Linear Model, GLM)을 설정하고, 인자 선택은 분산분석법(analysis of variance, ANOVA)을 통해 전진소거법 및 후진소거법을 사용하였으며, 통계분석은 SAS(version 9.1 for Windows)를 사용하였다. 본 연 구에 서 사용된 눈 다랑어와 황다랑어의 CPUE 자료는 곱의 오차 구조(multiplicative error structure)를 형 성하고 편 향된 확률분포를 가져(Quinn and Deriso, 1999)

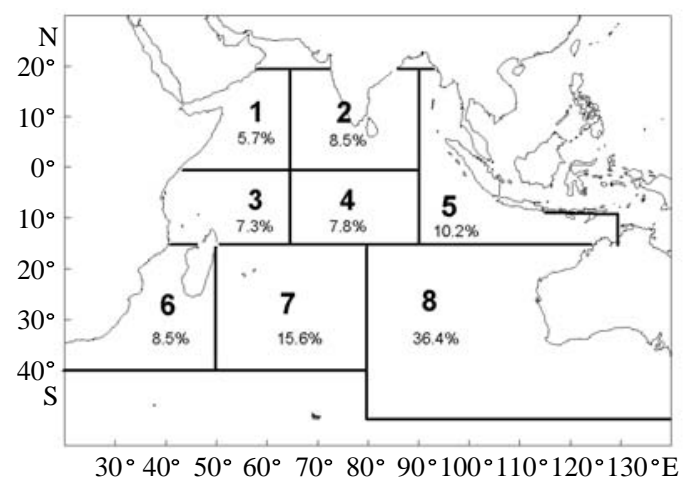

Fig. 2. Regional structure for standardizing CPUE in the Indian Ocean(Numbers of percent indicate the relative proportions of sub-area) (modified from Okamoto and Shono, 2006). 
대수정규분 포(log-normal distribution)를 가정하 고. 대 수변 환하였다.

일 반선 형 모델(GLM; Nelder and Wedderburn, 1972)은 CPUE 와 관련된 많은 인자들 중에서 영 향을 미치는 인자들을 분리시키는데 가장 보편 적으로 사용되는 방법이다(Maunder and Punt, 2004). 일반선형모델의 일 반식 은 식(1)과 같으 며, 종속변수의 기대값은 각 독립변수들의 선형 관 계를 가정한디(Guisan et al., 2002).

$$
g\left(\mu_{i}\right)=X_{i}^{T} \beta
$$

여기서 $g$ 는 미분함수이 고, $\mu_{i}=E\left(Y_{i}\right)$ 는 연 결함수, $X_{i}$ 는 종속변수 $i$ 번째 값에 대한 독립변수들의 벡 터, $\beta$ 는 추정 가능한 퐈라미터의 벡터, $Y_{i}$ 는 $i$ 번 째 반응변수이다. 식(1)으로부터 연 승어업에 의 한 눈다랑어와 황다랑어 의 CPUE 표준화에 적 용된 일 반선 형모 델은 식(2)와 같다. 본 연 구에 서 는 인도양다랑어 위원회(IOTC)가 일본 및 대만 의 CPUE 표준화 분석에 사용한 인자들 중에서 현재 우리나라 다랑어 연 승 어획자료에서 이용 가능 자료인 시기, 해역, 어 구특성, 표층수온 등 이 인자로서 고려되 었다(Okamoto et al., 2007; Liu et al., 2007; Wang et al., 2006). 종속변수인 CPUE 의 분산을 줄이기 위한 대 수변환시 어획 이 없을 때 $(\mathrm{CPUE}=0)$ 를 고려하여 CPUE 에 상수 (c=0.1) 를 더하였 다(Maunder and Punt, 2004). 모 든 독립변수들은 더미변수(dummy variable)에 의해 일 반선형모델에서 범주화되어 분석되었으 며, 환경변수인 표층수온 및 남방진 동계수는 연 속변수로 분석되었다.

$$
\log \left(U_{i j k l}+c\right)=\mu+Y_{i}+M_{j}+A_{k}+H_{l}+E+(\text { interaction })
$$

여 기서 $U_{i j k l}$ 는 낚시바늘 1,000 개 당 어 획미 수, c는 상수, $\mu$ 는 절편, $Y_{i}$ 는 $\mathrm{i}$ 년 도에 의해 CPUE 가 받은 영향, $M_{j}$ 는 $\mathrm{j}$ 달에 CPUE 가 받은 영향, $A_{k}$ 는 $\mathrm{k}$ 해역 에서 $\mathrm{CPUE}$ 가 받은 영향, $\mathrm{H}_{l}$ 은 $\mathrm{HBF}$ 로부터 $\mathrm{CPUE}$ 가 받은 영향, $\mathrm{E}$ 는 환경요인에 의해 $\mathrm{CPUE}$
가 받은 영향을 나타낸다. 또한, CPUE의 연도 $\left(Y_{i}\right)$ 에 대한 영향은 연간 풍도를 반영하기 때문 에 필수 인자로 포함하여(Maunder and Punt, 2004), 단일 인자들과 더불어 각 모델 내에서 주 요 요소들 사이의 상호작용(interaction)이 고려 되었다. 환경인자 $(\mathrm{E})$ 는 어획시점의 표층수온 및 남방진동계수를 입력하였으나, 남방진 동계수 는 분석과정에서 통계학적으로 유의하지 않아 소거하고 본 연구에서는 표층수온(T) 자료만을 선택하였다.

본 연구의 일반선형모델의 기본식인 식(2)에 서 소거법에 의해 적합화된 식은 식(3)과 식(4) 와 같으며, 식(3)은 눈다랑어, 식(4)는 황다랑어 의 CPUE 표준화를 위해 적 용된 식이다.

$$
\begin{aligned}
\log \left(U_{i j k l}+c\right)= & \mu+Y_{i}+M_{j}+A_{k}+H_{l}+T \\
& +(Y \times A)+(A \times H)+(M \times H)+(M \times T)
\end{aligned}
$$

$$
\begin{aligned}
\log \left(U_{i j k l}+C\right)= & \mu+Y_{i}+M_{j}+A_{k}+H_{l}+T \\
& +(Y \times A)+(Y \times T)+(M \times A) \\
& +(A \times H)+(T \times H)
\end{aligned}
$$

식(3)과 식(4)에서 추정된 $Y \times A$ 에 대한 최소제 곱 평 균치(least square mean, LSM)를 사용하여 식 (5) 와 같이 Shono and Ogura(1999)에 서 사용한 방법으로 표준화된 연간 CPUE 를 계산하였다.

$$
U_{i}=\sum W_{k} \cdot\left(e^{L S M\left(Y_{i} \times A_{k}\right)}-c\right)
$$

여기서 $U_{i}$ 는 $i$ 연 도에 대해 표준화된 CPUE, $W_{k}$ 는 $k$ 소해역 의 상대적 크기로, 대 상해 역(Fig. 2)에 대한 면적의 총합계 는 1 이 디 $\left(\sum W_{k}=1\right)$.

결 과
1971년부터 2007년까지 인도양해역 에서 우리
나라 연 승어업에 의한 눈다랑어의 연간 어획미
수는 Fig. 3 과 같은데 1978 년에 최고를 나타낸
이후 80 년대 중반과 90 년대 중반에 다소 증가하


였으나 전반적으로 감소추세를 보였고, CPUE 역시 어획 동항과 유사한 경항을 나타냈다 $(\mathrm{r}=$ $0.524, \mathrm{P}=0.001)$. 각 소해역별 어획변동을 살쪄 보면 소해역 1 부터 5 에 이르는 북부 및 중부 인 도양해역에서 대부분 어획되었다. 1970 년대 후
반에는 소해역 1 과 3 에서 높은 어획량을 보였으 나, 이후 감소하여 1990년대 후반부터는 대부분 의 소해역에서 어획미수가 크게 감소하였다. 소 해역별 CPUE 변 동은 소해역 7( $\mathrm{r}=0.038, \mathrm{P}>0.1)$ 을 제외한 대부분의 소해역에서 어획미수와 유

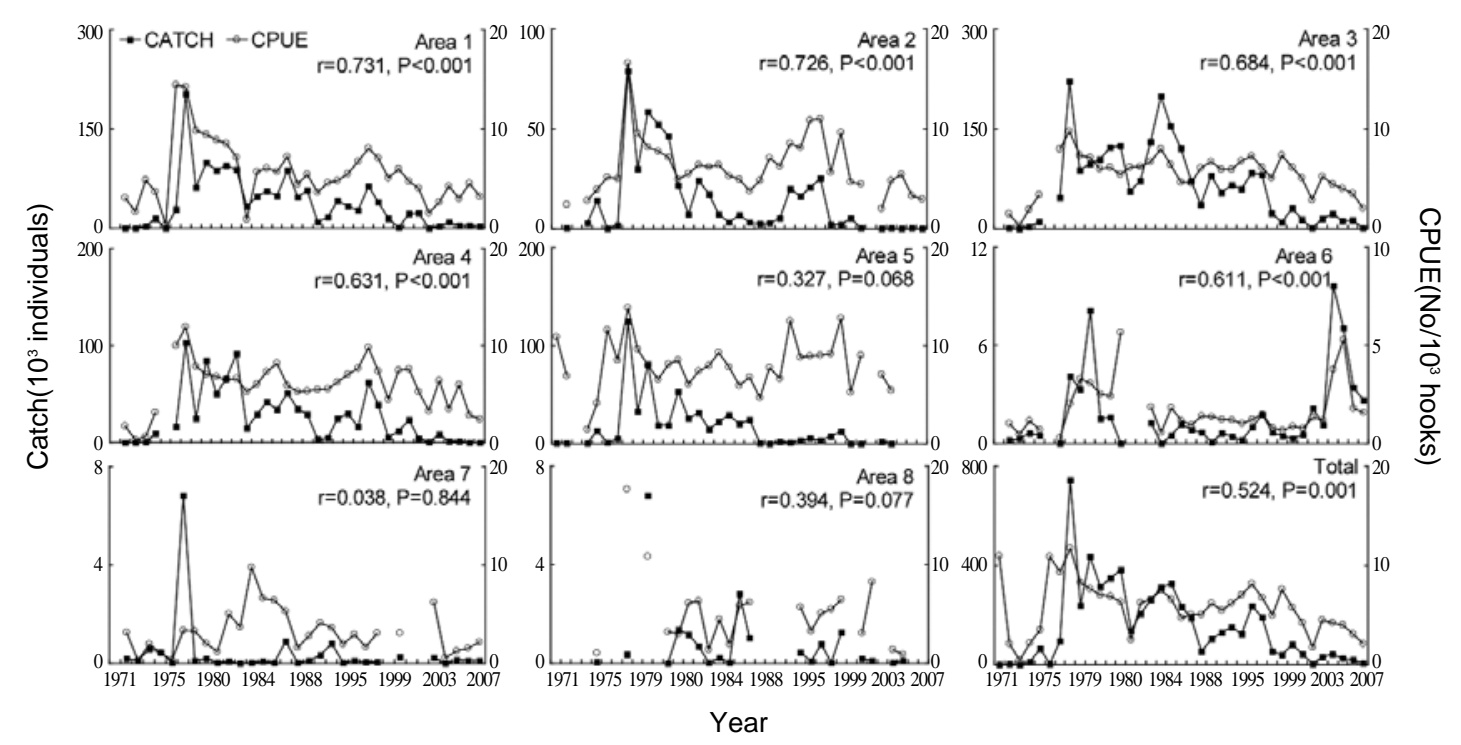

Fig. 3. Time series of annual catch and CPUE of bigeye tuna by sub-area in the Indian Ocean.

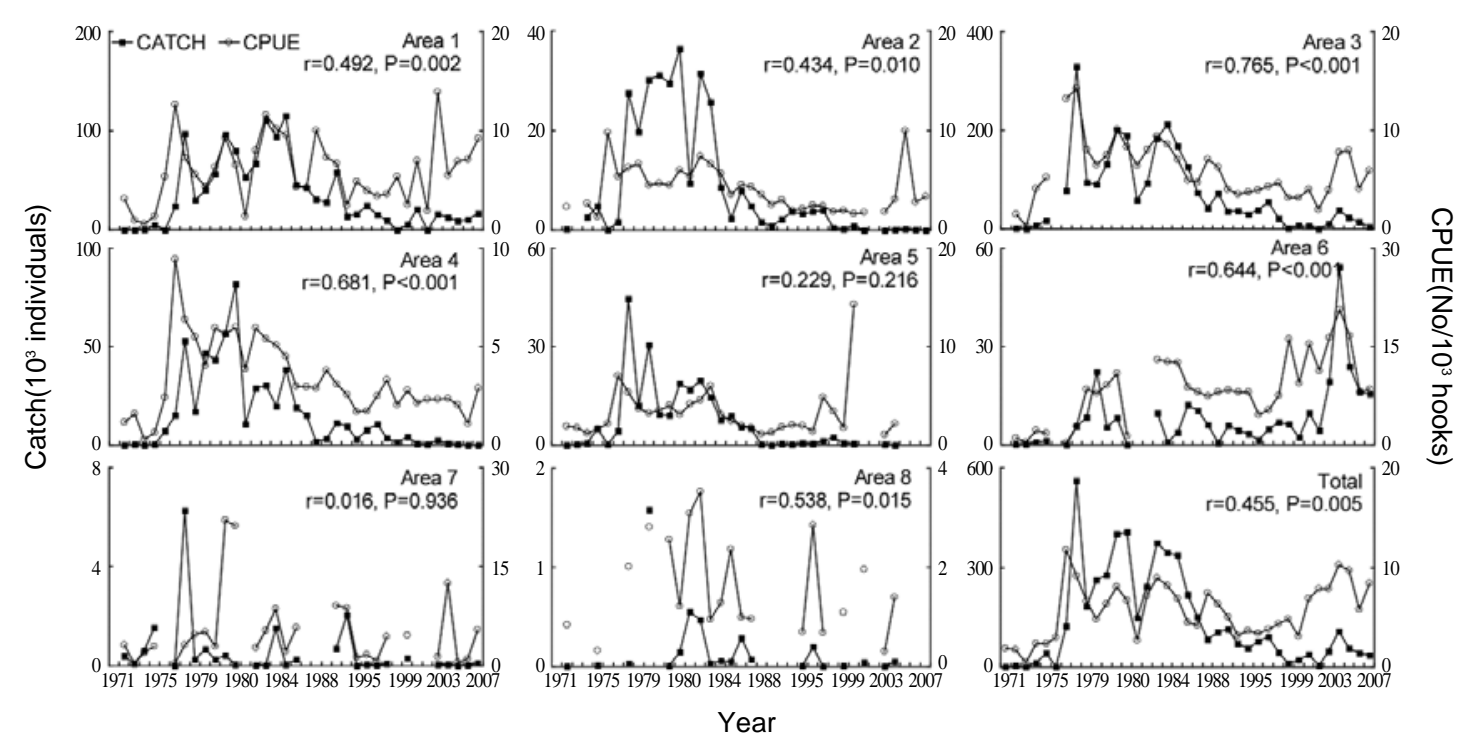

Fig. 4. Time series of annual catch and CPUE of yellowfin tuna by sub-area in the Indian Ocean. 
사한 경향을 나타냈다.

황다랑어의 어획미수 변 동은 Fig. 4 와 같은데, 연간 어획미수가 1978 년 에 최고어획을 나타낸 이후 지속적인 감소 추세를 나타내 어 눈다랑어 의 어획상황과 유사하였다. 황다랑어의 CPUE 는 1980 년 대 후반까지는 어 획변 동과 유사한 경 향을 나타냈으나 이후 증가하여 어획과는 반대 의 경항을 나타냈다 $(\mathrm{r}=0.455, \mathrm{P}=0.005)$. 각 소 해역별 어획은 소해역 1 과 3 에서 높았으며 상대 적으로 소해역 6 부터 8 까지에 이르는 남부 인 도 양해역에서는 거의 어획이 이루어지지 않았다. 특히 황다랑어 어획이 최고를 보인 1978 년 에는 전체 어획의 약 $60 \%$ 가 소해역 3 에서 어획되었 다. CPUE의 소해역별 변동은 상대적으로 높은 어획량을 보이는 북부 및 중부 인도양해역의 경 우 어획변동과 유사한 경향을 보였으나 어획이 낮은 남부 해역에서는 다소차이를 보였다.

1971 -2007 년 까지 전 체적 인 눈 다랑어와 황다 랑어의 어획은 대부분 북 - 중부 인도양해역을 중심으로 어획되고 있었으나, 1980년대 후반부 터는 어획이 급감하면서 어장의 위치도 중서부

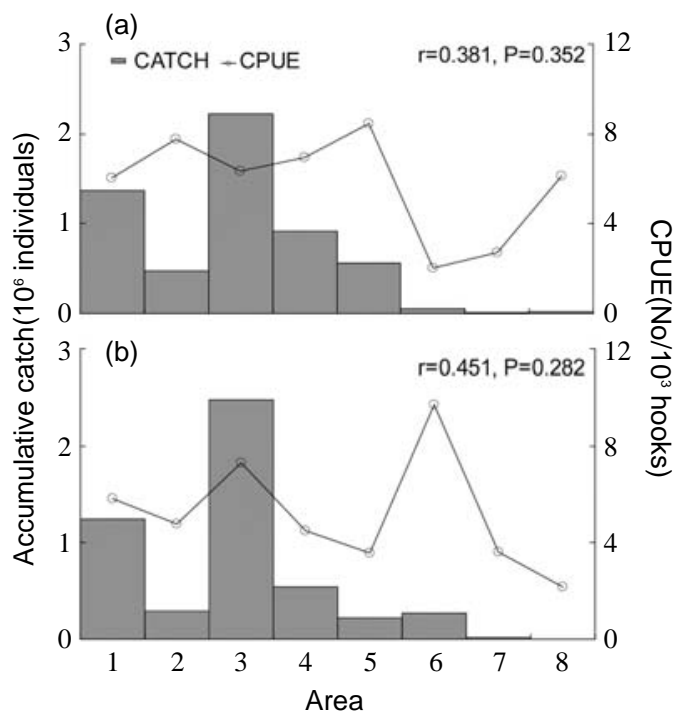

Fig. 5. The correlation between accumulative catch and CPUE of (a) bigeye and (b) yellowfin tunas by sub-area in the Indian Ocean.
인 도양해역으로 이 동하였다. 또한 Fig. 5 는 각 소해역별 눈다랑어 와 황다랑어에 대 한 어획변 동을 나타냈는데, 누적 어획량은 소해역 3 이 높 은 수준을 나타냈었고, $\mathrm{CPUE}$ 는 상대적으로 어 획이 적은 소해역 5 와 6 에서 각각 가장 높았다. 하지만, 소해역별 어획미수와 CPUE의 증감경 향은 유사성이 결여되 었더(눈다랑어 $\mathrm{r}=0.381$, $\mathrm{P}=0.352$; 황다랑어 $\mathrm{r}=0.451, \mathrm{P}=0.282$ ).

Table 1 은 일 반선형모델에 의한 1971 년부터 2007년까지 눈다랑어와 황다랑어의 연도, 해역, 어구, 환경인 자에 대한 ANOVA 결 과이 다. 각 인 자들의 자유도에 의해 세 부적으로 나뉘는 값들 의 차이는 Type $\mathbb{I I}$ 의 제곱합의 결과 값을 통해 살펴보았는데, 연 도, 개월, 해역, 어 구, 수온에 따 른 결 과값들은 눈다랑어와 황다랑어 모두 통계 학적으로 유의하게 나왔다. 특히 두 어종 모두 해역의 영향이 CPUE 에 가장 크게 영향을 미치 는 것으로 나타났다. 각 인 자들 의 상호작웅에 대 한 영향에 서 눈다랑어는 $\mathrm{Y} \times \mathrm{A}, \mathrm{A} \times \mathrm{H}, \mathrm{M} \times \mathrm{H}, \mathrm{M}$ $\times \mathrm{T}$ 에서만 유의한 결과가 나왔으며, 황다랑어 는 $\mathrm{Y} \times \mathrm{A}, \mathrm{Y} \times \mathrm{T}, \mathrm{M} \times \mathrm{A}, \mathrm{A} \times \mathrm{H}, \mathrm{T} \times \mathrm{H}$ 에서 유의한 결 과가 나왔다. 두 어종의 CPUE 관측치 와 추정 치에 대한 표준잔차는 Fig. 6 과 같이 모두 정규 분포를 따르는 것으로 나타났으므로 이 분석결 과가 타당한 것으로 판단되 었다.

Fig. 7 에서는 두 어 종의 표준화된(STD) CPUE 가 표준화되기 전(nominal) 과 비교해서 전체적 인 증감경향이 유사한 것으로 나타났다. 특히, 눈다랑어와 황다랑어의 CPUE는 표준화 전 과 후에서 공통적으로 1970년대 초반에는 음의 값 을 보인 후 1970 년 대 중 · 후반부터는 양의 값으 로 전환되 어 1980 년 대 중반까지 지 속되었다. 하 지 만, 1980년대 후반이후에는 눈다랑어와 황다 랑어의 CPUE 아노말리는 서로 반대의 경항을 보였다. 다시 말해, 눈다랑어 CPUE 아노말리는 1980 년대 후반 -1990 년대 후반까지 양의 값을 보인 후 2000년대 이후 음의 값으로 전 환되 었던 반면, 황다랑어는 동일한 기간동안 음의 값을 보 
인 후 전환되 어 최 근에 는 양의 값을 띠는 경 향이 두드러졌다.

눈다랑어의 CPUE 는 Fig. 7(a)와 같이 표준화 전과 후에서 모두1978년 이후 유사한 감소하는 경향을 보였다 $(\mathrm{r}=0.407, \mathrm{P}=0.001)$. 또한, 표준 화된 CPUE는 표준화 이전에 비해 변동성(CV) 이 다소 증가하여 유의한 분산 차이를 보였으며 $(\mathrm{F}=2.38, \mathrm{P}<0.01)$, 평균값은 유의한 감소를 나 타냈다 $(\mathrm{t}=4.49, \mathrm{P}<0.001)$. 눈다랑어의 CPUE 평 균값에 대한 아노말리는 표준화 전후의 CPUE 에서 모두 1970 년대 후반-1980년대 후반까지
와 1990 년 대 중반에 서 양의 값을 나타냈으며, 최 근 2000 년대에 들어서는 음의 값으로 전환되는 경항을 보였다. 황다랑어의 CPUE 는 Fig. 7(b) 와 같이 표준화 전과 후에서 변동경향이 유사했으 며 $(\mathrm{r}=0.463, \mathrm{P}=0.004)$, 전 반적인 변동은 감소 후 증가경향을 나타냈다. 표준화된 CPUE는 표 준화 이전에 비해 변동성 $(\mathrm{CV})$ 이 크게 증가하여 유의한 분산차이를 보였으며 $(\mathrm{F}=1.93, \mathrm{P}<0.05)$, 평 균값은 유 의하게 감 소하였 다 $(\mathrm{t}=4.86, \mathrm{P}$ <0.001). 황다랑어의 CPUE 아노말리는 1970 년 대 후반-1980년대 후반까지는 눈 다랑어에서와

Table 1. Results of ANOVA for standardizing CPUE

(a) Bigeye tuna

\begin{tabular}{|c|c|c|c|c|c|}
\hline Source & DF & Sum of Squares & Mean Square & F Value & $\operatorname{Pr}>F$ \\
\hline Model & 315 & 957.59 & 3.04 & 9.55 & $<.0001$ \\
\hline Error & 1,580 & 502.76 & 0.32 & & \\
\hline Source & $\mathrm{DF}$ & Type III SS & Mean Square & F Value & $\mathrm{Pr}>\mathrm{F}$ \\
\hline $\mathrm{Y}$ & 36 & 212.30 & 5.90 & 18.53 & $<.0001$ \\
\hline A & 7 & 72.40 & 10.34 & 32.50 & $<.0001$ \\
\hline $\mathrm{H}$ & 2 & 2.19 & 1.10 & 3.45 & 0.032 \\
\hline $\mathrm{T}$ & 1 & 2.69 & 2.69 & 8.46 & 0.004 \\
\hline $\mathrm{Y} \times \mathrm{A}$ & 211 & 183.48 & 0.87 & 2.73 & $<.0001$ \\
\hline $\mathrm{A} \times \mathrm{H}$ & 14 & 7.61 & 0.54 & 1.71 & 0.048 \\
\hline
\end{tabular}

(b) Yellowfin tuna

\begin{tabular}{|c|c|c|c|c|c|}
\hline Source & DF & Sum of Squares & Mean Square & F Value & $\operatorname{Pr}>F$ \\
\hline Model & 395 & 999.97 & 2.53 & 6.96 & $<.0001$ \\
\hline Error & 1,476 & 537.25 & 0.36 & & \\
\hline Corrected Total & 1,871 & $1,537.22$ & & & \\
\hline Source & DF & Type III SS & Mean Square & F Value & $\operatorname{Pr}>F$ \\
\hline $\mathrm{Y}$ & 36 & 30.76 & 0.85 & 2.35 & $<.0001$ \\
\hline M & 11 & 25.65 & 2.33 & 6.41 & $<.0001$ \\
\hline A & 7 & 58.69 & 8.38 & 23.04 & $<.0001$ \\
\hline $\mathrm{H}$ & 2 & 3.57 & 1.78 & 4.90 & 0.008 \\
\hline $\mathrm{T}$ & 1 & 1.41 & 1.41 & 3.88 & 0.049 \\
\hline $\mathrm{Y} \times \mathrm{A}$ & 209 & 206.64 & 0.99 & 2.72 & $<.0001$ \\
\hline $\mathrm{Y} \times \mathrm{T}$ & 36 & 28.61 & 0.79 & 2.18 & $<.0001$ \\
\hline $\mathrm{M} \times \mathrm{A}$ & 77 & 103.10 & 1.34 & 3.68 & $<.0001$ \\
\hline $\mathrm{A} \times \mathrm{H}$ & 14 & 11.02 & 0.79 & 2.16 & 0.007 \\
\hline $\mathrm{T} \times \mathrm{H}$ & 2 & 3.35 & 1.68 & 4.61 & 0.010 \\
\hline
\end{tabular}

where, Y: year, M: month, A: sub-area, H: number of hooks between floats,

$\mathrm{T}$ : sea surface temperature, DF: degree of freedom 


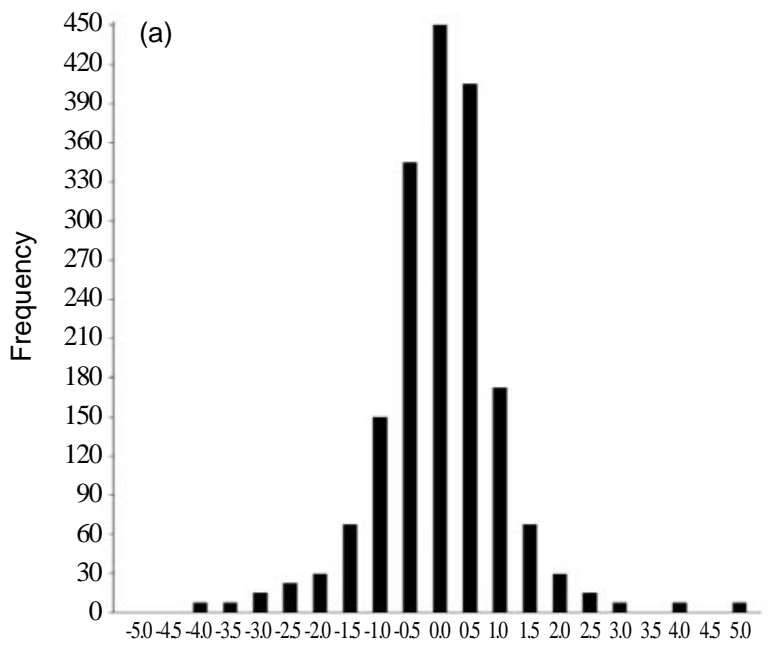

(b)

\section{Standardized residual}

Fig. 6. Histogram of residuals in GLM. (a) Bigeye tuna, (b) Yellowfin tuna.
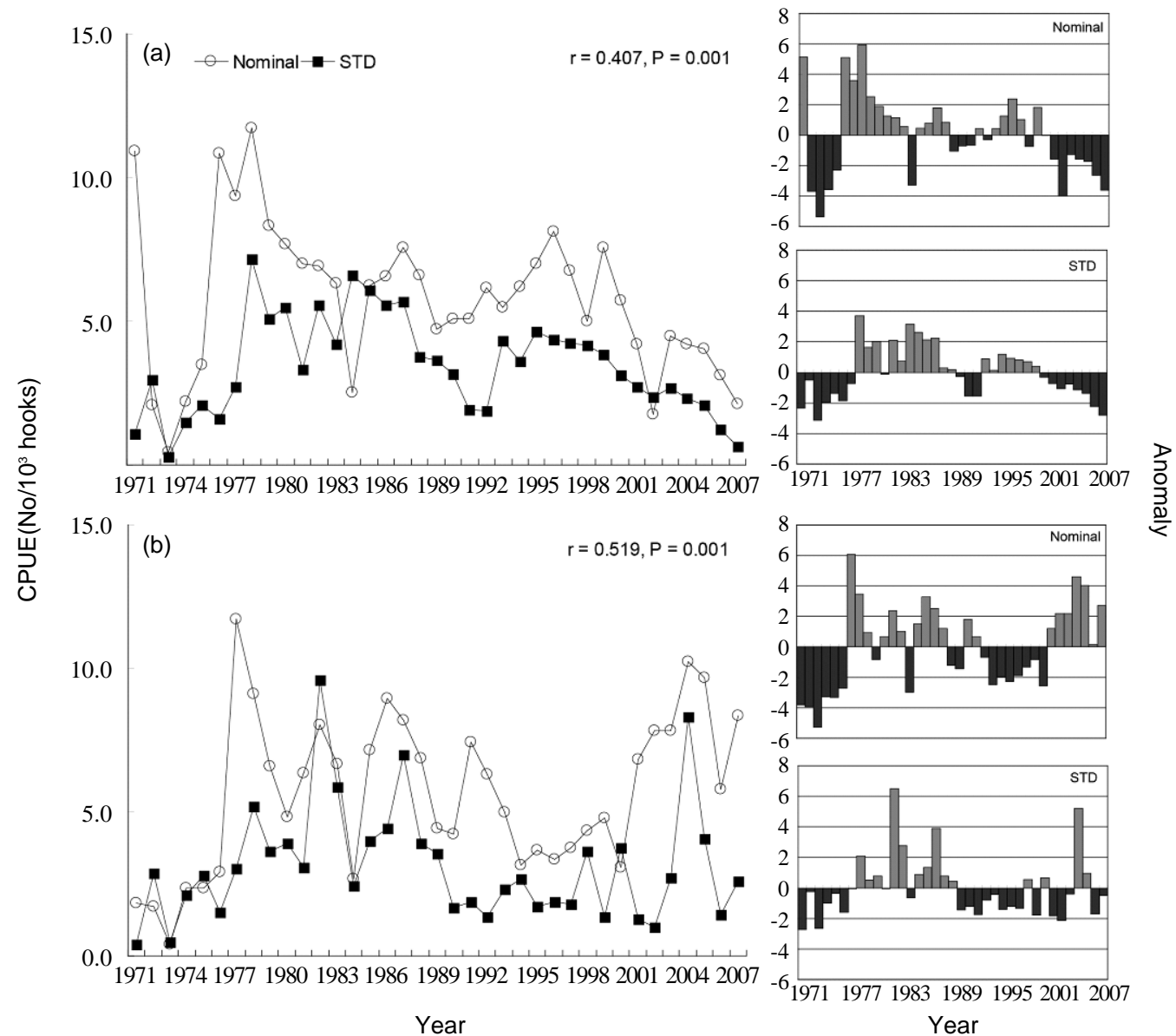

Year

$$
\text { Year }
$$

Fig. 7. Time series of nominal and standardized CPUEs (left panel) and their anomalies (right panel) for (a) bigeye and (b) yellowfin tunas in the Indian Ocean. STD indicates standardized CPUE. 

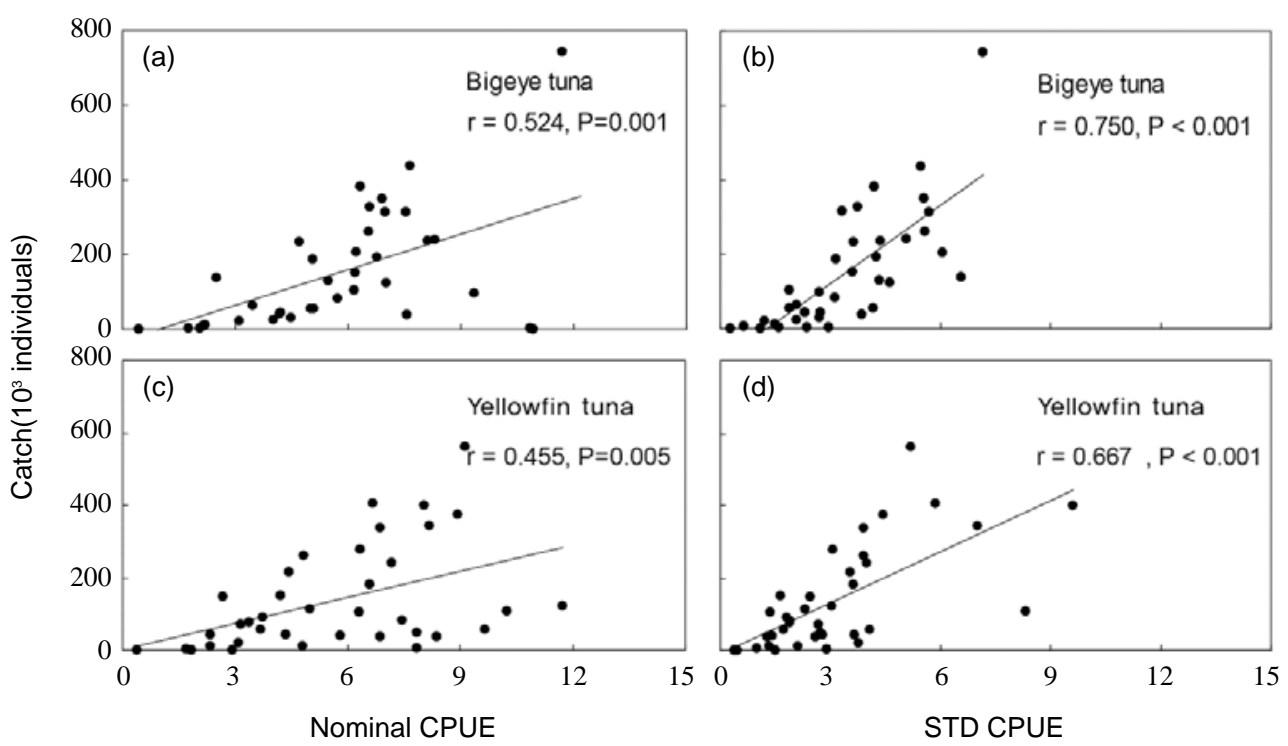

Fig. 8. Correlationships between catch and CPUEs for bigeye and yellowfin tunas in the Indian Ocean. (a) \& (c) Catch vs. Nominal CPUE, (b) \& (d) Catch vs. STD CPUE. STD means standardized CPUE.

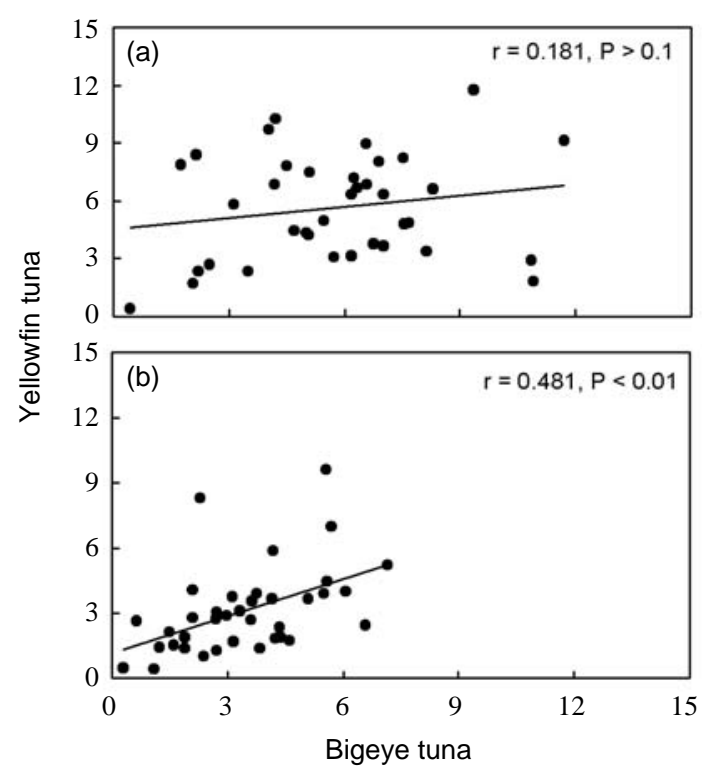

Fig. 9. Correlationships of CPUEs between bigeye and yellowfin tunas. (a) Nominal CPUE, (b) Standardized CPUE.

유사하게 양의 값을 보였으나, 이후 낮아져 1990 년대 후반까지는 음의 값을 나타냈다.
표준화된 CPUE는 Fig. 8 과 같이 표준화 이전 에 비해 실제 어획량 변 동을 보다 잘 설명하였 다. 눈다랑어의 실제 어획량의 변동은 표준화된 $\mathrm{CPUE}(\mathrm{r}=0.750)$ 가 표준화 이 전 $(\mathrm{r}=0.524)$ 에 비 해 $43 \%$ 향상된 상관성으로 설 명되 었으며, 황다 랑어의 경우에는 표준화된 $\operatorname{CPUE}(\mathrm{r}=0.667)$ 가 표준화 이전 $(\mathrm{r}=0.456)$ 대비 $47 \%$ 향상된 상관성 으로 설명되었다.

인도양해역 연 승어업의 주대상어종인 눈다랑 어 와 황다랑어 풍도사이의 상관관계는 Fig. 9 와 같이 표준화 이전은 상관성이 없었으나 $(\mathrm{r}=$ $0.181, \mathrm{P}>0.1)$, 표준화된 CPUE에서는 눈다랑어 의 CPUE 가 증가함에 따라 황다랑어의 CPUE 도 증가하는 통계학적으로 유의한 양의 상관성을 나타냈 다 $(\mathrm{r}=0.481, \mathrm{P}<0.01)$.

\section{고 찰}

어획능률이 일정하다고 가정할 때 수리적으 로 $\mathrm{CPUE}$ 는 상대적인 자원의 풍도지수를 나타 낸다. 그러나 실제 CPUE는 조업 시기, 환경, 어 구 등의 요인들로 인해 영향을 받으므로 표준화 
과정이 수행되지 않으면, 자원량이 과대 혹은 과 소 추정되어 자원관리의 실패를 야기 시킬 수 있 다. 따라서 자원평가의 기본 입력자료가 되는 $\mathrm{CPUE}$ 의 표준화가 평가 이전에 우선시되어야 한다(Maunder, 2001). 그려나CPUE를 표준화 하 는데 있어서 사용되 는 자료는 출어한 어선의 일 별 혹은 분기별 조업일지의 자료에 의 존하기 때 문에 사용할 수 있는 자료가 한정되 거나 각 국가 또는 분석자들에 따라 달라질 수 있다. Gavaris(1980)는 국가; 어구형태, 톤급, 월, 조업 해역, 연 도를 CPUE에 영향을 주는 인 자로 간주 하였으며, Olsen and Laevastu(1983)는 연 승어업 CPUE 에 영향을 미치는 인자를 32 가지로 기술 하고 모델에 결합시킨 바 있다. 그러한 인자들 중에서 침수시간 낚시바늘간의 간격, 낚시바늘 크기, 줄 깊이, 미끼, 양망기계 성능차이 등이 주 영향인 자로 제시되었다. 본 연 구에서는 뜸과뜸 간의 낚시바늘수 $(\mathrm{H})$, 조업해구 면적(A), 어장 수 온(T) 등의 조업상황과 관련된 인자와 더불어 계 절성 $(\mathrm{M})$ 및 연변동 $(\mathrm{Y})$ 이 눈다랑어와 황다랑어 의 CPUE에 영향을 주는 인자로 제시되었다. 또 한, 단일 인자간의 상호작용을 통해서 도 연 승어 업 의 CPUE 가 영향을 받는 것으로 나타났다. 다 시 말하면, 눈다랑어와 황다랑어의 CPUE는 공 통적으로 연도별 어장의 영항 $(\mathrm{Y} \times \mathrm{A})$ 과 소해역 별 낚시바늘수 차이 $(\mathrm{A} \times \mathrm{H})$ 의 복합적 상호작용 을 통해서 영향을 받는 것으로 해석된 다.

대상자원 의 상태를 평가할 때 어획노력량과 어획량 자로만으로 풍도를 설명하기에는 한계 가 있다(Polacheck, 2006). 이에 대 상자원의 풍도 에 영항을 미치는 인자들(계절성, 어 구특성, 조 업해역 등)을 고려한 CPUE 표준화는 대상자원 의 풍도 진단에서 보다 과학적인 접 근이다. 특 히, 본 연 구의 Fig. 7 에서와 같이 인 도양해역 다 랑어연 승어 업에 서 눈 다랑어와 황다랑어의 $\mathrm{CPUE}$ 는 표준화를 통해서 자원풍도를 과대평 가 할 오류의 가능성을 줄일 수 있다.

표준화 후의 CPUE 가 표준화 전 의 CPUE 경향
과 유사하게 나타났으나, 실제 어 획상황을 설 명 하는데 는 향상된 상관성을 보였다. 이는 인도양 해역 연승어업의 표준화된 CPUE를 활용하여 계 절성 및 어장 수온 등의 외부환경 변 동에 대한 시나리오별 눈다랑어 및 황다랑어 미래 풍도 및 어 획량 예 측이 가능할 것으로 생각된다.

자원평가 및 관리에 있어서 바로 전년도의 CPUE 값만이 사용된 다면 현 재 우리나라의 어획 량이 다른 조업국에 비해 낮은 상태이기 때 문에 무시할 정도의 값이다. 그러나 과거의 자원상태 의 변동양상에 따른 전 반적인 자원상태를 추정 하거나 더욱 정확한 자원평 가를 위해서는 우리 나라의 CPUE 자료가 필수적인 자료이다. 조업 일지의 보고 누락이나 자료입력시 실수 등으로 발생되는 자료의 신빙성의 문제는 이를 보정할 만한 베이지안이나 우도함수와 같은 통계학적 기 법들이 표준화 이전에 선행되어야 할 것이다. 또한 다랑어를 어획하는데 영항을 미치는 여러 외부인자들에 대한 조사 및 자로수집도 병행되 어야 한다.

눈다랑어 의 자원상태는 인 도양을 제 외한 태 평 양 및 대서양에서 과도어획으로 인한 남획상 태에 있는 것으로 평 가되고 있다(Maunder and Harley, 2005; ICCAT, 2005; Hampton et al., 2006a). 황다랑어는 현 재 과도어획으로 인한 남 획 상태 에 있으므로, 어획량을 조속히 줄여야 한 다는 연구결과가 있다(IOTC, 2007; Hoyle and Maunder, 2005; ICCAT, 2004; Hampton et al., 2006b). 인도양의 눈다랑어 및 황다랑어의 자원 평 가에 사용되는 CPUE는 일본과 대 만의 어획 자로에서 얻어진다. IOTC 보고서(2007)는 1960 년 부터 일 본 CPUE 와 1980 년 이 후의 대 만CPUE 표준화를 통한 자원상태 평가결 과 황다랑어의 자원은 안정적인 상태로 평 가되 었으나, $1960-$ 1980년 기간의 대만 CPUE 자로가 추가될 경우 황다랑어 자원상태는 감소경항을 보였다. 이는 대 만 CPUE 가 1960 -1980년 기간에 는 크게 감 소하는 경항을 보였고, 1980 년 대 이후부터는 상 
대적으로 증가한 어획으로 인해 CPUE가 증가 하는 경향을 나타냈기 때문인 것으로 해석되었 다(IOTC, 2007). 본 연 구에서는 표준화된 우리나 라 CPUE 를 통해 살펴본 눈 다랑어 와 황다랑어 는 Fig. 7 에 서와 같이 전 반적으로 감소하는 경향 이 두드러젔다. 이와 같이 자원상태가 CPUE의 증감에 반응하기 때 문에 대상자원 을 어획하는 대부분의 어획자료가 자원평 가에 고려되 어져야 할 것이다. Fig. 1(a) 에서 보는 바와 같이 스페인, 프랑스 등의 국가에서도 어획량이 크게 증가하 고 있으며 특히, 우리나라의 경 우에 는 1970 년 대 중반부터 80년대 초반까지는 전체 어획량의 절 반 이상을 어획하였으므로 1970년부터 1980년 까지의 자원상태를 정 확하게 평가하기 위해서 는 우리나라CPUE 자로가 사용되 어야 한다.

향후의 인도양해역 다랑어 연승어업 의 CPUE 표준화 연 구에서는 다음의 세 가지 인자들에 대 한 영향이 추가되어야 할 것이다. 첫째, 눈다랑 어와 황다랑어의 생태학적 특성 등을 고려한 인 자들을 추가할 필 요성이 있다. 예로, 눈다랑어는 수심 $150 \mathrm{~m}$ 이하의 상대적으로 깊은 곳에서 어획 이 되기 때문에(IOTC, 2007), 수심별 수온의 영 향이 CPUE 에 영향을 미칠 것으로 퐌단된 다. 둘 째, 본 연구에서 사용된 또 하나의 환경인자인 남방진동계수는 주로 태평양의 변화를 나타내 기 때 문에, 인 도양의 변화와는 잘 맞지 않았으므 로 인도양의 환경을 고려한 인도양진 동계수 (Indian scillation index, IOI) 가 필요할 것으로 여 겨진다. 마지막으로, 국가별 CPUE를 표준화해 야 할 것이다. 동해역 에서 다랑어 를 대상으로 조 업에 참여하는 국가수가 점차 늘어나고 있으며, 1970년대 중반의 경 우에는 우리나라와 같이 전 체 어획량의 절반이상을 차지하는 어획자료를 포함시켜 자원평가를 수행할 필요가 있기 때문 에 각 조업국의 어획상황을 모두 고려하여 표준 화된 CPUE를 도출하는 작업이 국제수산기구 차원에서 추진되 어야 할 것이며, 본 연구결 과가 그 단계에서 유용하게 활용될 것으로 기 대된 다.

\section{결 론}

개체군역 학을 이용한 자원평 가는 상대적 풍 도지수인 CPUE를 기본자료로 평가되고 있다 (Maunder and Punt, 2004). 표준화된 방법에 의해 수집되는 과학조사자료는 모든 어업에 적용될 수 없기 때 문에 상업적 어업에 의해 수집되 는 어 획자료를 사용하고 있으나, 이 자로는 계절, 어 장 등의 외부적인 영향으로 쉽게 변 동될 수 있기 때문에 변동요소들을 제 거하여 일 반화된 어획 자로가 사용된다. 본 연구에서는 인 도양해역 의 눈다랑어 및 황다랑어의 자원평 가를 위해 우리 나라 다랑어 연승어업 의 CPUE 를 표준화하였다. 연도, 해역, 어구, 환경인자에 대해 일 반선 형모 델을 사용하여 CPUE 를 표준화시켰으며, 그 결 과 눈다랑어와 황다랑어 두 종의 $\mathrm{CPUE}$ 는 해역 의 영향이 가장 큰 것으로 나타났고, 연도별 어 장의 영항 $(\mathrm{Y} \times \mathrm{A})$ 과 소해역별 낚시바늘수 차이 $(\mathrm{A} \times \mathrm{H})$ 의 상호작웅이 복합적으로 영향을 미치 는 것으로 해석된다. 표준화된 CPUE는 표준화 전의 CPUE 에 비해 실제 어획량의 변동을 보다 잘 설명하였다. 표준화된 CPUE를 통한 눈다랑 어 와 황다랑어의 풍도는 전 반적인 감소경향을 나타내었고, 표준화된 두 종의 CPUE의 아노말 리를 보면 1970년대 후반부터 1980년대 중반까 지는 CPUE 가 높은 수준을 나타냈으나, 최근 2000 년 대에 들어서는 낮은 수준을 나타냈다. 인 도양해역의 눈다랑어 와 황다랑어 의 자원량 변 동을 고려한 자원관리에 있어서 우리나라의 어 획자료는 1970 년대 중반부터 10 여년간 인 도양 다랑어 연승어업의 어획의 상당량을 어획했기 때 문에 중요한 자료로 사용될 수 있을 것이다.

\section{참고문헌}

FAO, 1997. Review of the state of world fishery resources: Marine Resources Service. FAO Fisheries Circular., No. 920, pp. 173.

FAO, 2003. Managing fishing capacity of the world tuna fleet. FAO Fisheries Circular., No. 982, pp. 82. 
FAO, 2007. Capture production 2005. FAO Yearbook of Fishery Statistics, Vol. 100/1. pp. 539.

Gavaris, S., 1980. Use of a multiplicative model to estimate catch rate and effort from commercial data. Can. J. Fish. Aquat. Sci., 37, 2272 - 2275.

Guisan, A., Jr. T.C. Edwards and T. Hastie, 2002. Generalized linear and generalized additive models in studies of species distributions: setting the scene. Ecol. modell., 157, $89-100$

Hampton, J., A. Langley and P. Kleiber, 2006a. Stock assessment of bigeye tuna in the Western and Central Pacific Ocean, including an analysis of management options. WCPFC-SC2-2006/SA WP 2, pp. 103.

Hampton, J., A. Langley and P. Kleiber, 2006b. Stock assessment of yellowfin tuna in the Western and Central Pacific Ocean, including an analysis of management options.WCPFC-SC2-2006/SA WP 1, pp. 99.

Hilborn, R. and C.J. Walters, 1992. Quantitative fisheries stock assessment: choice, dynamics and uncertainty. Chapman and Hall, New York, pp. 570.

Hinton, M.G. and H. Nakano, 1996. Standardizing catch and effort statistics using physiological, ecological, or behavioral constraints and environmental data, with an application to blue marlin(Makaira nigricans) catch and effort data from Japanese longline fisheries in the Pacific. Inter-Am. Trop. Tuna Comm. Bull., 21, $171-200$.

Hoyle, S.D. and M.N. Maunder, 2005. Status of yellowfin tuna in the Estern Pacific Ocean in 2004 and outlook for 2005. Inter-Amer. Trop. tuna Comm. Stock Assess. Rep., pp. 102.

ICCAT(International Commission for the Conservation of Atlantic Tunas), 2005. Report of the 2004 ICCAT bigeye tuna stock assessment session. 58(1), pp.110.

IOTC(Indian Ocean Tuna Commssion), 2007. Report of the Ninth Session of the IOTC Working Party on Tropical Tunas. IOTC-2007-WPTT-R[E], pp. 44.

Liu, H., S. Chang and S. Chang, 2007. Catch rate standardization runs for yellowfin yuna caught by
Taiwanese deep sea longline fishery in the Indian Ocean using generalized linear model and generalized linear mixed model. IOTC-2007-WPTT-19, pp. 13.

Maunder, M.N., 2001. A general framework for integrating the standardization of catch per unit of effort into stock assessment models Can. J. Fish. Aquat. Sci., 58, $795-803$.

Maunder, M.N. and S.J. Harley, 2005. Status of bigeye tuna in the Estern Pacific Ocean in 2004 and outlook for 2005. Inter-Amer. Trop. tuna Comm. Stock Assess. Rep., pp. 206.

Maunder, M.N. and A.E. Punt, 2004. Standardizing catch and effort data: a review of recent approaches. Fish. Res., 70, $141-159$.

Maunder, M.N. and P.J. Starr, 1995. Rock lobster standardized CPUE analysis. New Zealand Fisheries Assessment Res. Doc. 95/11. [Available from National Institute of Water and Atmospheric Research (NIWA), Greta Point, P.O. Box 297, Wellington, N.Z.], pp. 28.

Nelder, J.A. and R.W.M. Wedderburn. 1972. Generalized linear models. J. R. Statist. Soc., 137, 370 - 384.

Okmoto, H. and H. Shono, 2006. Japanese longline CPUE for bigeye tuna in the Indian Ocean up to 2004 standardized by GLM applying gear material information in the model. IOTC-2006-WPTT-1, pp. 17.

Okmoto, H., H. Shono and T. Nishida, 2007. Japanese longline CPUE for yellowfin tuna in the Indian Ocean up to 2005 standardized by GLM. IOTC2007-WPTT-10, pp. 23.

Olsen, S. and T. Laevastu, 1983. Factors affecting catch of longlines, evaluated by a simulation model of longline fishing. Draft manuscript for ICES Fish Capture Comm., pp. 13.

Polacheck, T., 2006. Tuna longline catch rates in the Indian Ocean: Did industrial fishing result in a $90 \%$ rapid decline in the abundance of large predatory species?, Mar. Pol., 30(5), $470-482$.

Polacheck, T., R. Hilborn, and A.E. Punt, 1993. Fitting surplus production models: comparing methods and 
measuring uncertainty. Can. J. Fish. Aquat. Sci., 50, $2597-2607$.

Quinn, II T.J. and R.B. Deriso, 1999. Quantitative fish dynamics. Oxford University Press. New York, pp. 542.

Shono, H. and M. Ogura, 1999. The standardized skipjack CPUE including the effect of searching devices, of the Japanese distant water pole and line fishery in the Western Central Pacific Ocean.
ICCAT-SCRS/99/59, pp. 18.

Wang, S., S. Chang, T. Nishida and S. Lin, 2006. CPUE standardization of Indian Ocean swordfish from Taiwanese longline fishery for Data up to 2003. OTC-2006-WPB-09, pp. 13.

2008 년 6 월 30 일 접수

2008 년 7 월 16 일 1 차 수정

2008 년 8 월 7 일 2 차 수정

2008 년 8 월 7 일 수리 